\title{
Periodontal Status and Quality of Life: Impact of Fear of Pain and Dental Fear
}

\author{
Casey D. Wright, ${ }^{1,2,3}$ Daniel W. McNeil, ${ }^{1,2,3}$ Cierra B. Edwards, ${ }^{1,2,3}$ Richard J. Crout, $^{2,4}$ \\ Katherine Neiswanger, ${ }^{2,5}$ John R. Shaffer, ${ }^{2,6}$ and Mary L. Marazita ${ }^{2,5,6}$ \\ ${ }^{1}$ Department of Psychology, West Virginia University, 53 Campus Drive, P.O. Box 6040, Morgantown, WV 26506, USA \\ ${ }^{2}$ Center for Oral Health Research in Appalachia (COHRA), University of Pittsburgh, Pittsburgh, PA 15219, USA \\ ${ }^{3}$ Department of Dental Practice \& Rural Health, Center for Oral Health Research in Appalachia (COHRA), School of Dentistry, \\ West Virginia University, One Medical Center Drive, Morgantown, WV 26506, USA \\ ${ }^{4}$ Department of Periodontics, Center for Oral Health Research in Appalachia (COHRA), School of Dentistry, \\ West Virginia University, One Medical Center Drive, Morgantown, WV 26506, USA \\ ${ }^{5}$ Department of Oral Biology, Center for Craniofacial and Dental Genetics, School of Dental Medicine, \\ University of Pittsburgh, Bridgeside Point Suite 500, 100 Technology Drive, Pittsburgh, PA 15219, USA \\ ${ }^{6}$ Department of Human Genetics, Graduate School of Public Health, University of Pittsburgh, 130 De Soto Street, \\ Pittsburgh, PA 15261, USA
}

Correspondence should be addressed to Daniel W. McNeil; dmcneil@wvu.edu

Received 4 November 2016; Accepted 15 January 2017; Published 9 March 2017

Academic Editor: Gaspare Palaia

Copyright (C) 2017 Casey D. Wright et al. This is an open access article distributed under the Creative Commons Attribution License, which permits unrestricted use, distribution, and reproduction in any medium, provided the original work is properly cited.

Background. Oral health-related quality of life (OHRQoL) is impacted by periodontal disease and orofacial pain. There is a limited research examining the impact of avoidance of care or physiological arousal related to the fear of pain response on periodontalrelated OHRQoL. Methods. Data are from the Center for Oral Health Research in Appalachia family-based study focusing on 1,339 adults. Measures included a modified Periodontal Screening and Recording Index across sextants of dentition, dental fear survey, Fear of Pain Questionnaire-9, and Oral Health Impact Profile-14. Structural equation modeling was used to estimate the effects of periodontal disease screening indicators on OHRQoL including the mediating role of dental fear while accounting for fear of pain. Results. A significant total effect was found for the mandibular anterior sextant, components of dental anxiety/fear, and indicators of OHRQoL (pain and discomfort, $\beta=.165, p=.001$; psychosocial impact, $\beta=.199, p<.001$ ). The maxillary anterior region was significantly associated with pain discomfort $(\beta=.116, p=.017)$ and functionality $(\beta=.130, p=.011)$. Conclusions. Findings provide a granular perspective of periodontal disease indicators and OHRQoL. Dental avoidance/anticipatory fear and physiological arousal mediate OHRQoL in individuals who have indicators of periodontal disease in sextants that may be visible and susceptible to higher pain and psychosocial impact.

\section{Introduction}

Chronic periodontal disease is defined as inflammation of the gingiva extending into the adjacent attachment apparatus. Clinical features may include edema, erythema, gingival bleeding upon probing and/or suppuration, and attachment loss [1]. Prevalence rates range from 25 to 54 percent in gingivitis (early disease with no attachment loss) to 43 percent with chronic periodontitis determined by one or more sites of attachment loss [2]. Established risk factors for developing periodontal disease include increasing age, tobacco use and alcohol consumption, genetic factors, obesity, poorly controlled diabetes, and psychological stress $[3,4]$. Bouchard et al. [5] established a conceptual framework of risk for periodontal disease. The relations between risk and causal chains and causal networks leading to chronic periodontitis were highlighted, including a broad range of factors, ranging from distal ones (e.g., lifestyle) to biomarkers [5]. Additionally, research has indicated a link between localized periodontitis and enamel pearls suggesting that enamel pearls may be a causative factor, especially in maxillary molars [6]. Understanding chronic periodontitis as "among the most 
complex noncommunicable diseases" [5, p. 1] leads one to consider a wide range of factors, such as quality of life, that may provide additional insight into the clinical treatment and management of pain and disease.

Periodontal conditions often are not recognized in their early stages [7]. As periodontal disease progresses, signs such as swollen and bleeding gums and, ultimately, tooth mobility due to loss of support become apparent and possibly painful $[8,9]$. A likely deterrent for managing such conditions could involve avoidance of brushing, flossing, or engaging in routine dental care. Due to its sequela, periodontal disease is a major cause of tooth loss in adults [10]. Although there is no evidence for causality, periodontal disease is associated with broader systemic health concerns including osteoporosis, rheumatoid arthritis, cardiovascular disease, and cognitive loss [11-13]. Women with periodontal disease also are more likely to have pregnancy complications [14].

In clinical periodontal applications, after a periodontal evaluation that includes probing depths and location of gingival margin (clinical attachment level), treatment includes removal of supragingival and subgingival plaque and calculus, as well as scaling and root planning. If treatment is not successful, antimicrobial agents or surgical treatment may be necessary [1]. Behavioral approaches are used to address long-term tertiary prevention, including oral hygiene instructions, adherence with suggested periodontal interventions, and counseling for control of risk factors (e.g., cessation of smoking and coping with stress) [1].

Although a variety of intervention methods exist, many individuals do not seek treatment for periodontal disease until it is at an advanced stage, in which tooth loss is common. Research is needed, therefore, at earlier periods when periodontal involvement is less advanced (e.g., gingivitis) and when screening indicators (e.g., attachment levels) may be the harbinger of more progressive disease (e.g., periodontitis). Additionally, few investigations have been directed to a precise understanding of periodontal status in regions of the oral cavity and their relation to quality of life or into the mechanisms of avoidant behavior and periodontal disease.

Periodontal disease has been linked to lower quality of life [15]. Quality of life refers to one's perceptions about life, both positive and negative, as a result of the cultural context in which one lives [16]. Quality of life encompasses several domains, including psychological functioning and social relationships among others. Oral health-related quality of life (OHRQoL, i.e., quality of life specific to oral health and the impacts of oral health) has been shown to be reduced in patients with periodontal disease [17-19]. Reduction in OHRQoL may be due to increased pain, tooth loss, and resultant loss of function. As an example, individuals with periodontal disease report negative impacts of their oral health on their overall functioning such as greater functional limitation, physical pain, and psychological discomfort [20]. Due to the deleterious effects of periodontal disease on health and quality of life, it is important to identify potentially modifiable factors that may mediate these relations. Understanding such indirect pathways may provide areas for future interventions to help alleviate the more direct negative effects on quality of life.
Given the greater burden of periodontal and other oral diseases in northern Appalachia relative to other regions and the general population in the USA [21], population samples from this region can provide an important basis to understand the relationship between oral diseases and OHRQoL and, in addition, allow assessment of additional psychosocial factors. Greater dental care-related anxiety and fear [22] are associated with poorer oral health status [23] possibly due, in part, to decreased care-seeking. Fears about pain during dental treatment have been identified as a major component of dental fear [24] and thus may indirectly affect dental treatment utilization. Mehrstedt et al. [25] and more recently Vermaire et al. [26] studied the effects of dental carerelated fear and anxiety on quality of life and found that dental fear/anxiety contributes significantly to disease burden. Additionally, a study on the effects of dental anxiety/fear in quality of life in patients with temporomandibular disorders found that those with higher levels of dental anxiety/fear had poorer OHRQoL [27]. Given its prevalence across the population [22], including in north central Appalachia, dental care-related anxiety and fear are a particularly relevant psychosocial factor, along with fear of pain, that may affect the relation between periodontal disease and OHRQoL.

This rationale is supported by the documented association of dental fear and periodontal disease indicators. $\mathrm{Ng}$ and Leung [28] examined dental fear and its relation to periodontal clinical attachment levels and oral health-related quality of life. Greater levels of dental care-related anxiety and fear were associated with lower clinical attachment levels. Increased levels of dental fear also were related to poorer OHRQoL [28]. This relation was found in their sample of Hong Kong adults but has not been investigated in other population groups. Additionally, dental care-related anxiety and fear were treated as a single construct, while others assert the benefit of a more granular view [22]. Finally, the indirect link of fear of pain has yet to be explored in its relation to periodontal disease, dental fear, and OHRQoL.

The current study aimed to elucidate associations among fear of pain, dental fear, periodontal disease, and OHRQoL in the COHRA1 sample from north central Appalachia, associated with the Center for Oral Health Research in Appalachia (COHRA). More specifically, the direct and indirect effects of periodontal disease indicators on OHRQoL were investigated, while accounting for fear of pain and aspects of dental care-related anxiety and fear. There were two hypotheses. First, greater indications of periodontal disease (i.e., deeper PSR probing depths) in specific sextants were expected to be related to poorer OHRQoL. Second, it was hypothesized that components of dental care-related anxiety and fear, while accounting for fear of pain, would mediate the association between periodontal disease indicators and OHRQoL.

\section{Methods}

2.1. Participants. The COHRA1 protocol and sample have been previously described [29]. The COHRA1 project examined the genetic, psychosocial, and microbiological differences among families (comprising at least one parent-child pair) from rural West Virginia and Pennsylvania. Data were 
TABLE 1: Sample demographics.

\begin{tabular}{|c|c|c|}
\hline & $M / N$ & $\mathrm{SD} / \%$ \\
\hline Age & 34.34 & 9.52 \\
\hline \multicolumn{3}{|l|}{ Sex } \\
\hline Men & 487 & $36.37 \%$ \\
\hline Women & 852 & $63.63 \%$ \\
\hline \multicolumn{3}{|l|}{ State of residence } \\
\hline West Virginia & 881 & $65.80 \%$ \\
\hline Pennsylvania & 458 & $34.20 \%$ \\
\hline \multicolumn{3}{|l|}{ Income } \\
\hline less than 10,000 & 269 & $20.10 \%$ \\
\hline 10,000 to 14,999 & 203 & $15.20 \%$ \\
\hline 15,000 to 24,999 & 224 & $16.70 \%$ \\
\hline 25,000 to 34,999 & 157 & $11.70 \%$ \\
\hline 35,000 to 49,999 & 158 & $11.80 \%$ \\
\hline 50,000 to 74,999 & 81 & $6.00 \%$ \\
\hline 75,000 to 99,999 & 38 & $2.80 \%$ \\
\hline 100,000 to 149,999 & 19 & $1.40 \%$ \\
\hline 150,000 to 199,999 & 2 & $0.10 \%$ \\
\hline 200,000 or more & 6 & $0.40 \%$ \\
\hline Missing & 182 & $13.60 \%$ \\
\hline \multicolumn{3}{|l|}{ Education } \\
\hline No high school diploma & 190 & $14.2 \%$ \\
\hline High school diploma/GED & 556 & $41.5 \%$ \\
\hline Technical school & 171 & $12.8 \%$ \\
\hline Some college, no degree & 161 & $12.0 \%$ \\
\hline Undergraduate degree & 131 & $9.80 \%$ \\
\hline Graduate degree & 63 & $4.70 \%$ \\
\hline Missing & 67 & $5.00 \%$ \\
\hline
\end{tabular}

collected via interviews (i.e., demographic, oral health, and medical and family history), self-report questionnaires (e.g., health survey, dental fear survey, perceived stress, health locus of control, and nicotine dependence), and intraoral health assessments, which included periodontal probing among other disease indicators.

The present study utilized participants of age 18 and older with measures of periodontal probing depths, fear of pain, dental fear, and oral health-related quality of life. The present sample consisted of 1,339 individuals $(63.6 \%$ females and $36.4 \%$ males) with a mean age of 34.3 ( $\mathrm{SD}=9.5$; range $=18-93$ ). Table 1 describes participant characteristics. Consistent with demographics of this region of Appalachia, the participants were predominantly Caucasian $(88.4 \%)$ but included $7.7 \%$ African Americans, $0.7 \%$ Hawaiian/Pacific Islanders, and 3.2\% other racial/ethnic groups or missing.

\subsection{Psychosocial Assessments}

Dental Fear Survey (DFS). The DFS is a 20-item, Likerttype, self-report instrument targeted at detecting individual differences related to dental fear [30]. The three subscalesavoidance and anticipatory fear, fear of specific dental stimuli, and physiological arousal-allow for a multilevel understanding of an individual's dental fear. The three subscales were used in this study to provide a more detailed analysis of dental care-related anxiety and fear. Various studies have been conducted to assess the psychometrics of the DFS [31, 32]. There is evidence for the internal consistency of the DFS ( $\alpha=$ .80) [33] and data demonstrating overall construct validity $[34,35]$. Furthermore, researchers have cross-validated the three-factor structure of the DFS in numerous cultural groups $[36,37]$.

Fear of Pain Questionnaire-9 (FPQ-9). The FPQ-9 is a nineitem self-report questionnaire; the three subscales (fear of severe pain, fear of minor pain, and fear of medical pain) reflect the structure of the FPQ-9 parent instrument, the Fear of Pain Questionnaire-III [38]. Data from each of the FPQ-9 individual subscales and the total score can be interpreted to indicate adequate internal consistency $(\alpha=.84$, severe pain; $\alpha=.72$, minor pain; $\alpha=.73$, medical pain; $\alpha=.83$, total score). The FPQ-9 is scored by summing three item scores for each of the three subscales and a total score can be calculated by totaling all nine items. This study utilized the FPQ-9's higher order factor structure (three subscales loading onto a total score). The short instrument was shown to be highly correlated with the original FPQ-III $(r=.94-.97)$ suggesting concurrent validity to the already validated FPQ-III [38].

Oral Health Impact Profile-14. The COHRA1 protocol utilized the OHIP-14, a self-report instrument comprised of 14 items related to OHRQoL. The original version of the OHIP included 49 items [39] loading onto seven subscales. The OHIP-14 has demonstrated internal consistency $(\alpha=.90)$, test-retest reliability ( $r=0.79-0.94)$, and construct validity in numerous samples around the world [40-42]. Due to lack of evidence for adequate factorial validity for the OHIP-14, a number of factor structures have been tested via confirmatory factor analyses. Later researchers utilized a stepwise regression analysis to reduce the original OHIP scale to only two items per subscale. The reduced-item scale still accounted for $94 \%$ of the variance in the original OHIP, allowing greater ease of administration and clinical utility [43]. More recently, John and colleagues argued that the original OHIP and other OHRQoL assessments can be reduced to four major dimensions (i.e., oral function, orofacial pain, psychosocial impact, and orofacial appearance) [44-46], although the OHIP-14 does not assess the latter factor. Dos Santos et al. [47] proposed the use of a three-factor structure (psychosocial impact, pain and discomfort, and functional limitations) for the OHIP-14 that parallels the John et al. [46] factors, which was utilized in the current study.

2.3. Periodontal Screening and Recording Index (PSR). The COHRA1 periodontal screening indicators as well as the training and calibration of examiners were previously described [48, 49]. Modified Periodontal Screening and Recording (PSR) [50] indices were produced through oral health assessments conducted by a licensed and calibrated dentist or dental hygienist. To record probing depths, the mouth was divided into sextants. Gingival crevices around each tooth were examined, and researchers recorded the deepest probing depth found in each sextant. Probing depths 


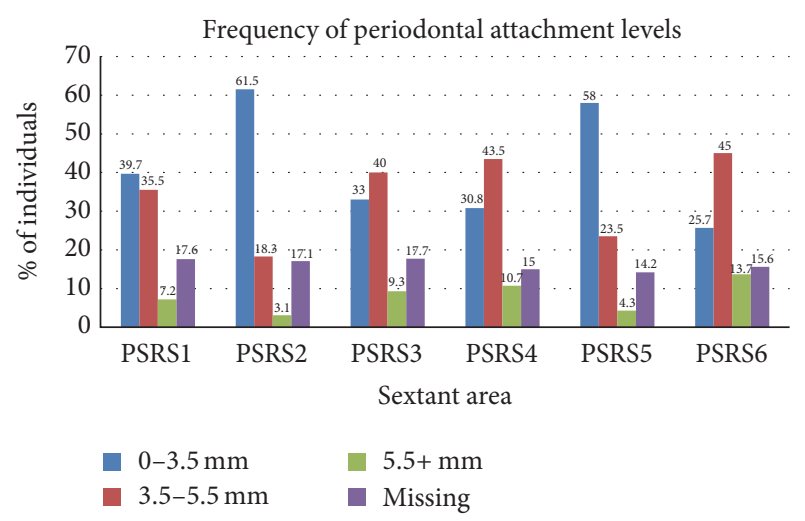

Figure 1: Note. $N=1,339$ adults.

were categorized as shallow (i.e., $<3.5 \mathrm{~mm}$ ), moderate (i.e., $3.5 \mathrm{~mm}-5.5 \mathrm{~mm}$ ), or deep (i.e., $>5.5 \mathrm{~mm}$ ). If all teeth in a sextant were missing, they were treated in two ways as in Shaffer et al. [49] and Landry and Jean [50]. In one model, these areas were treated as "missing related to periodontal disease" (i.e., treated as having a probing depth of $>5.5 \mathrm{~mm}$ ) and another model as "missing due to other, nonperiodontal disease factors" (i.e., treated as having a probing depth of $<$ $3.5 \mathrm{~mm}$ ). Figures 1 and 2 depict the distribution of frequency of probing depths across sextants.

2.4. Analytic Approach. In order to test the aforementioned hypotheses, a structural equation modeling (SEM) approach was utilized. Two models-missing due to periodontal disease and missing due to nonperiodontal factors-were tested. SEM includes integrating two major componentsa measurement approach based on factor analysis (i.e., confirmatory factor analysis) and a structural path analysis [51]. By combining factor analysis and path analysis, relations between latent (and other) variables can be examined, while taking into account measurement error. More traditional methods of analysis such as analysis of variance (ANOVA) and regression assume all variables and constructs are perfectly measured, often resulting in inaccurate or underestimated coefficients and $p$ values $[51,52]$. When all else is equal, decreased and accounted for measurement error leads to less biased results via SEM.

Model Assumptions. SEM analyses follow certain assumptions, including that variable relations are linear, arise from independent observations, have residuals that are normally distributed, have general equality of variance across variables, and exhibit no signs of extreme multicollinearity and that missing data are handled appropriately $[53,54]$. These assumptions were assessed using histograms and descriptive statistics. Assumptions based on linear relations, normality of residuals, and equality of variance were satisfied. Because the COHRA1 data included household information, the independence assumption was possibly violated, but the present models included only adults (18 and older), which reduced the possible consequences due to lack of independence.

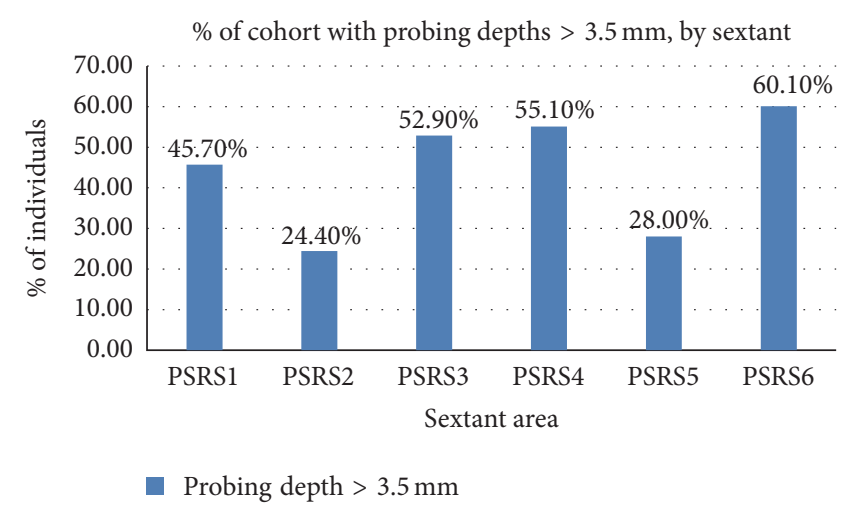

Figure 2: Note. Edentulism assumed to be due to periodontal disease, although models with and without this assumption were tested in SEM.

In order to account for missing data (beyond the missing due to periodontal issues mentioned earlier), a Full Information Maximum Likelihood method (FIML) in MPLUS 7.4 [55] was incorporated. Previous literature has argued FIML to be more robust in handling missing data than other (e.g., listwise deletion, pairwise deletion, or mean replacement) methods [56]. To assess model fit, specific indices included the root mean square error of approximation (RMSEA), comparative fit index (CFI), Tucker-Lewis index (TLI), and standardized root mean square residual (SRMR). Each of these indices provide unique information and are suspect to various assumptions (e.g., CFI can be inflated due to model complexity), thus the use of all four. Previous researchers suggest heuristic cutoff guidelines for good model fit including a RMSEA value below .06, a CFI and TLI above .90 , and SRMR below $.08[57,58]$.

Measurement Approach. Each of the self-report instruments (FPQ-9, DFS, and OHIP-14) were individually analyzed via confirmatory factor analyses to establish the measurement portion of the model. That is, confirmatory factor analysis (and later combined with multiple regression analyses) allows the measurement error inherent in each variable to be accounted for and provides less biased results [51, 52]. In each case, MPLUS 7.4 [55] modification indices were used to allow for improved model fit (and thereby a reduction in measurement error). The FPQ-9 factor structure tested included the nine items loading onto three subscales which loaded onto a higher order total score as theoretically derived [38].

In order to provide more granular interpretations, the three DFS component subscales were utilized, instead of a total score. Thus, the 19 items (excluding the omnibus item 20) loaded onto their appropriate subscales.

As previously noted, various factor structures have been proposed for the OHIP-14. The present study utilized the three subscales (psychosocial impact, pain and discomfort, and functional limitations) outlined by dos Santos et al. [47]. After an exploratory factor analysis of the current data and testing various factor structures, it was determined that the three-factor solution [47] best fit the data. 


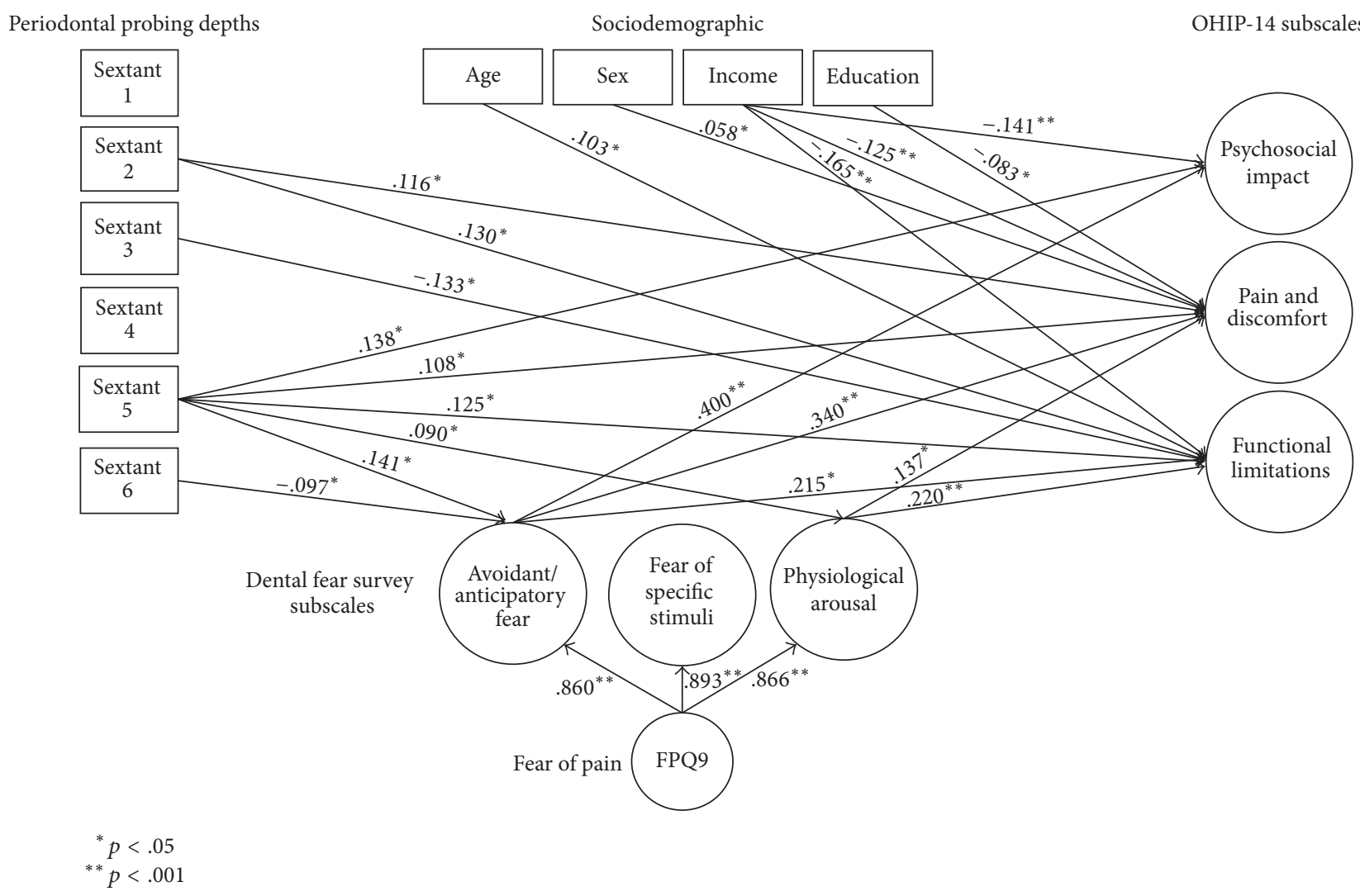

FIgURE 3: Note. Edentulism assumed to be due to periodontal disease in the model.

Path Analysis (Full SEM). Figure 3 includes the full structural equation model used in this study. Directionality was implied in the model by having OHIP-14 subscales regressing on the periodontal indicators and on the DFS subscales which regressed on the FPQ-9. In order to correct for a nonpositive definite matrix, the mean of the PSR sextant six was fixed to 0.876 . Both of the aforementioned hypotheses were tested by first estimating the associations between PSR indicators and OHIP-14 subscales. In addition, in order to test the second hypothesis, the relationship of fear of pain (FPQ-9) and dental fear (DFS subscales) as well as the relationship between the DFS subscales and OHIP-14 subscales were estimated. After results indicated a unique relationship between the mandibular anterior sextant (sextant five), the avoidance and anticipatory fear subscale of DFS, and the OHIP-14 subscales, indirect effect analyses also were utilized. In all cases, there was an alpha cutoff of .05.

\section{Results}

Figure 1 displays the model tested in this study. Confirmatory factor analyses with modification indices are outlined in Table 2. The FPQ-9 fit the data well using the higher order (three subscales loading onto a total fear of pain score) factor structure. The three DFS subscales of avoidant/anticipatory fear, fear of specific stimuli, and physiological fear fit the data by itself as well $(\mathrm{RMSEA}=.041$; CFI $=.920$; $\mathrm{TLI}=.911$; SRMR $=.057)$. Finally, the three subscale factor structure as
TABLE 2: Model fit indices produced by confirmatory factor analyses.

\begin{tabular}{lcccc}
\hline Model & RMSEA & CFI & TLI & SRMR \\
\hline Fear of Pain & 0.063 & 0.973 & 0.951 & 0.033 \\
Questionnaire-9 (FPQ-9) & 0.051 & 0.961 & 0.954 & 0.051 \\
$\begin{array}{l}\text { Dental fear survey (DFS) } \\
\text { Oral Health Impact }\end{array}$ & 0.055 & 0.958 & 0.944 & 0.036 \\
Profile-14 (OHIP-14) & & &
\end{tabular}

Note. The DFS factor structure did not include the higher order total score but rather the individual items loading onto the three subscales.

described by dos Santos et al. [47] produced good model fit. Although a complex model, the final SEM also produced adequate model fit. Due to only minor differences in the two models-missing due to periodontal issues and missing due to nonperiodontal issues-results from the former model are presented.

3.1. Hypothesis 1: PSR Indicators and OHIP-14 Subscales. The full structural equation model included a number of statistically significant results. The probing depths in the maxillary anterior and mandibular anterior regions (sextants two and five) were shown to have significant relationships with OHIP-14 subscales. More specifically, the maxillary anterior sextant was significantly associated with pain and discomfort as it relates to quality of life $(\beta=.116, p=.017)$ as well functional limitations $(\beta=.130, p=.011)$. The 
TABLE 3: Relationships between FPQ-9 total scores and the three DFS subscales.

\begin{tabular}{lcccc}
\hline FPQ-9 total score as a predictor & $\beta$ & SE & Est./SE & $p$ \\
\hline Avoidant/anticipatory fear & 0.860 & 0.019 & 46.347 & $<.001$ \\
Fear of specific stimuli & 0.893 & 0.014 & 64.465 & $<.001$ \\
Physiological fear & 0.866 & 0.018 & 47.504 & $<.001$ \\
\hline
\end{tabular}

Note. Standardized beta values are according to Mplus 7.4 STDYX standardization.

mandibular anterior region had the broadest impact as far as number of significant relationships. This sextant had a significant association with the psychosocial impact subscale of the OHIP-14 $(\beta=.138, p=.001)$, with pain and discomfort $(\beta=.108, p=.019)$ and with the functional limitations subscales $(\beta=.125, p=.010)$. One region, sextant three, was negatively associated with functionality $(\beta=-.133, p=.020)$. All significant relationships are portrayed in Figure 1 using solid-line arrows.

\subsection{Hypothesis 2: Mediating Relationship of Dental Fear.} Consistent with prior research, and as expected, the FPQ9 latent total score was predictive of all three DFS subscales. Table 3 describes these relations. Regarding the three subscales from the DFS, the fear of specific stimuli did not associate significantly with any of the three OHIP14 subscales. Physiological responses to dental fear were associated with the pain and discomfort subscale $(\beta=.137$, $p=.048)$ and the functional limitations subscale $(\beta=.220$, $p=.011)$. Some of the largest effects were associated with the avoidant and anticipatory fear subscale. This scale related to the psychosocial OHIP-14 subscale $(\beta=.400, p<.001)$ as well as the pain and discomfort subscale $(\beta=.340, p<$ $.001)$. Another relationship of significance was between the avoidance and anticipatory fear subscale and the functional limitations scale $(\beta=.215, p=.018)$. The avoidance and anticipatory fear subscale also played a noticeable role in the mediation between PSR indicators and OHIP-14 scores. Sextant six was negatively associated with avoidance and anticipatory fear $(\beta=-.097, p=.048)$.

As noted, the main effect of the mandibular anterior sextant on the pain and discomfort subscale was statistically significant (Main effect $\beta=.108, p=.019$ ). The total mediating effect via the sextant-avoidance-pain pathway also was significant (indirect effect via avoidance $\beta=.048, p=$ .007 ; total effect $\beta=.165, p=.001$ ). In addition, there was a mediating effect associated with the mandibular anterior sextant, avoidance and anticipatory fear, and the psychological impact related to quality of life (main effect $\beta=.138, p=.001$; indirect effect via avoidance $\beta=.056$, $p=.006$; total effect $\beta=.199, p<.001)$. The total effects of the mandibular anterior sextant and the quality of life subscales were also mediated by the physiological arousal DFS subscale. These specific indirect effects, although not statistically significant, contributed to the overall total indirect effect of this particular sextant on the pain and discomfort as well as the functionality subscales of the OHIP14. In the model in which edentulous sextants were not assumed to be due to periodontal issues, the $p$ value for the direct effect between the physiological arousal subscale and the pain and discomfort subscale changed from $p=.048$ to $p=.056$. The overall indirect effect was, however, still significant.

\section{Discussion}

The current study examined the relations among periodontal disease indicators, fear of pain, dental fear, and oral healthrelated quality of life. The role of avoidant behavior and anticipatory fear, as a component of dental care-related anxiety and fear, emerged as a significant factor that impacts OHRQoL. Previous research has indicated the association of periodontal disease measures with impaired OHRQoL $[18,19]$. The present approach, however, added more granular information which helps to explain which regions of the oral cavity may be most associated with OHRQoL, at least in early stages of periodontal involvement. Additional research should further examine these relations and the mechanisms that may be involved in quality of life. Also notable were the findings that the anterior regions of the mouth, and in particular the mandibular anterior sextant, play interesting roles in affecting quality of life related to oral health.

The present study confirmed the importance of fear of pain in dental fear. Individuals who may have high indication of periodontal disease in the mandibular anterior area and high levels of fear of pain also may also have especially high levels of avoidant behavior and anticipatory fear related to oral healthcare. This in turn may have a compounding effect on these individuals' quality of life as it relates to oral health. Future studies and interventions could target reducing fear of pain and modification of avoidant behavior in individuals with indicators of periodontal disease and assess the impact on OHRQoL.

The role of components of dental care-related anxiety and fear as mediators between periodontal disease indicators and quality of life is interesting in light of the previous research by $\mathrm{Ng}$ and Leung [28]. Indicators of periodontal disease may be easier for individuals to ignore in the posterior areas of the oral cavity, but once they are evident in the anterior regions, they are more difficult to deny, which may lead to increased dental fear, due to the knowledge that professional dental care is imperative. Fear of pain is a compounding factor in such instances, of course, as periodontal disease may be associated with pain, and anticipation of necessary professional care may lead to fears about experiencing pain during procedures such as scaling and root planning.

Although not a statistically significant indirect effect, part of the total mediating effect between sextant five and quality of life was due to the physiological arousal DFS subscale. In particular, physiological arousal mediated and had a direct effect on the pain and discomfort OHIP-14 subscale as well as the functional limitation subscale. Future interventions and subsequent research could be aimed at reducing the physiological arousal that often accompanies dental fear, fear of pain, and even the manifestation of pain itself. By reducing fear responses, individuals with possible periodontal disease may be less likely to avoid treatment or may tolerate 
treatment more easily due to the reduction in physiological activation.

These findings have clinical relevance in terms of the importance of fear and pain and their interaction, in oral health care settings $[59,60]$. Past research has indicated a need for proper training in anesthetic techniques for dentists [61] and an interest in learning about the most effective techniques [62]. Updates of topical and local anesthetic agents are available, along with newer strategies for delivering local anesthetics [63-65].

Boyce and colleagues [63] suggest that fear and anxiety continue to be the main reason patients avoid or do not follow up with dental care. They suggest that oral health care professionals have the responsibility of educating patients on the many advances to minimize pain and sharing how the developments in anesthesia practiced in dentistry can help alleviate both pain and anxiety. These pharmacological advances have implications for periodontal disease and its treatment.

\section{Limitations}

Results must be understood in light of the limitations in the study design. First, the periodontal phenotype was based on measurement of a PSR index, which is a nonclinical measure related to periodontal disease. Because the PSR indexing used pocket depth to estimate attachment loss rather than measuring attachment directly, it may underestimate attachment loss especially in older patients with severe gingival recession [50]. Given that the present population is relatively young, however, severe gingival recession is unlikely to be a common problem. Thus, estimates based on probing depth may be a good surrogate for disease activity [48]. In terms of measurement, the choice of the OHIP-14 did not allow for a measure of orofacial appearance, which may be important in terms of the visibility of the two sextants that related to OHRQoL in this study.

While the sample is a unique one from north central Appalachia, it does not necessarily represent the entirety of the diverse Appalachian region. Reports of avoidance behavior were gleaned from a DFS subscale, but no actual dental attendance data were incorporated. Future research might explore how specific dental appointment attendance may mediate the relation between periodontal disease and OHRQoL. The present analyses did not account for possible clustering due to adults living in the same household. As a result, the relationships are probably unbiased, but the inferences about these relationships (e.g., beta coefficients and $p$ values) could be inflated. In addition, even with 1,339 participants, with as complex a model as was included in this study, it is possible that the study was underpowered and that other relationships could have been otherwise detected.

\section{Conclusions}

The current study was designed to examine associations between periodontal status and oral health-related quality of life and to test the mediating effects of dental fear as influenced by fear of pain. The resulting evidence suggests that there are unique relationships between the maxillary anterior and mandibular anterior sextants and OHRQoL. In addition, when accounting for fear of pain, aspects of dental fear mediate the relationship between periodontal measures and OHRQoL, especially via avoidant behavior and anticipatory fear. These results merit further investigation into clinical applications and how pharmacological and behavioral interventions for fear of pain and dental fear may encourage patients with periodontal disease to seek treatment early and thereby improve their overall quality of life.

\section{Competing Interests}

The authors declare that they have no competing interests.

\section{Acknowledgments}

The authors thank the participants in this study, as well as the partner facilities in West Virginia and Pennsylvania that provided support for this project. Appreciation also is extended to the West Virginia Rural Health Education Partnerships program and community advisory boards for this project. The current research teams in West Virginia (Linda Brown, Stella Chapman, Dr. Elizabeth Kao, Michael Law, and Karolyn Reel) and Pittsburgh (Jayme Zovko, Wendy Carricato, Zelda Dahl, Jessica Ferraro, Helen Hawkey, Jennifer Maurer, Keri Simonette, and Andrea Warzynski) and their predecessors are acknowledged with thanks. This research was supported by the National Institute for Dental and Craniofacial Research/National Institutes of Health (R01 DE014899).

\section{References}

[1] American Academy of Periodontology, "Parameters of care," Journal of Periodontology, vol. 71, no. 5, supplement, pp. 847883, 2000.

[2] J. D. Beck and S. J. Arbes, "Epidemiology of gingival and periodontal diseases," in Carranza's Clinical Periodontology, F. A. Carranza, M. G. Newman, H. H. Takei, and P. R. Klokkevold, Eds., pp. 110-129, WB Saunders, Philadelphia, Pa, USA, 10th edition, 2006.

[3] J. Bergström and H. Preber, "Tobacco use as a risk factor," Journal of Periodontology, vol. 65, no. 5, pp. 545-550, 1994.

[4] R. J. Genco and W. S. Borgnakke, "Risk factors for periodontal disease," Periodontology 2000, vol. 62, no. 1, pp. 59-94, 2013.

[5] P. Bouchard, M. C. Carra, A. Boillot, F. Mora, and H. Rangé, "Risk factors in periodontology: a conceptual framework," Journal of Clinical Periodontology, vol. 44, no. 2, pp. 125-131, 2017.

[6] U. Romeo, G. Palaia, R. Botti, A. Del Vecchio, G. Tenore, and A. Polimeni, "Enamel pearls as a predisposing factor to localized periodontitis," Quintessence International, vol. 42, no. 1, pp. 6971, 2011.

[7] J. Cunha-Cruz, P. P. Hujoel, and N. R. Kressin, "Oral healthrelated quality of life of periodontal patients," Journal of Periodontal Research, vol. 42, no. 2, pp. 169-176, 2007.

[8] L. LeResche and S. F. Dworkin, "The role of stress in inflammatory disease, including periodontal disease: review of concepts 
and current findings," Periodontology 2000, vol. 30, no. 1, pp. 91103, 2002.

[9] S. Seltzer, I. B. Bender, and M. Ziontz, "The interrelationship of pulp and periodontal disease," Oral Surgery, Oral Medicine, Oral Pathology, vol. 16, no. 12, pp. 1474-1490, 1963.

[10] R. C. Williams, "Periodontal disease," New England Journal of Medicine, vol. 322, no. 6, pp. 373-382, 1990.

[11] J. Beck, R. Garcia, G. Heiss, P. S. Vokonas, and S. Offenbacher, "Periodontal disease and cardiovascular disease," Journal of Periodontology, vol. 67, no. 10, pp. 1123-1137, 1996.

[12] R. I. Garcia, M. M. Henshaw, and E. A. Krall, "Relationship between periodontal disease and systemic health," Periodontology 2000, vol. 25, no. 1, pp. 21-36, 2001.

[13] B. Wu, B. L. Plassman, R. J. Crout, and J. Liang, "Cognitive function and oral health among community-dwelling older adults," Journals of Gerontology, Series A: Biological Sciences and Medical Sciences, vol. 63, no. 5, pp. 495-500, 2008.

[14] X. Xiong, P. Buekens, W. D. Fraser, J. Beck, and S. Offenbacher, "Periodontal disease and adverse pregnancy outcomes: a systematic review," BJOG, vol. 113, no. 2, pp. 135-143, 2006.

[15] I. Needleman, C. McGrath, P. Floyd, and A. Biddle, "Impact of oral health on the life quality of periodontal patients," Journal of Clinical Periodontology, vol. 31, no. 6, pp. 454-457, 2004.

[16] D. L. Patrick and P. Erickson, Health Status and Health Policy: Quality of Life in Health Care Evaluation and Resource Allocation, Oxford University Press, Oxford, UK, 1993.

[17] E. Bernabé and W. Marcenes, "Periodontal disease and quality of life in British adults," Journal of Clinical Periodontology, vol. 37, no. 11, pp. 968-972, 2010.

[18] H. Jansson, A. Wahlin, V. Johansson et al., "Impact of periodontal disease experience on oral health-related quality of life," Journal of Periodontology, vol. 85, no. 3, pp. 438-445, 2014.

[19] J. Durham, H. M. Fraser, G. I. McCracken, K. M. Stone, M. T. John, and P. M. Preshaw, "Impact of periodontitis on oral health-related quality of life," Journal of Dentistry, vol. 41, no. 4, pp. 370-376, 2013.

[20] S. K. S. Ng and W. K. Leung, "Oral health-related quality of life and periodontal status," Community Dentistry and Oral Epidemiology, vol. 34, no. 2, pp. 114-122, 2006.

[21] D. W. McNeil, R. J. Crout, and M. L. Marazita, "Oral health in Appalachia," in Appalachian Health and Well-Being, R. L. Ludke and P. J. Obermiller, Eds., pp. 275-294, University Press of Kentucky, Lexington, Ky, USA, 2012.

[22] D. W. McNeil and C. L. Randall, "Dental fear and anxiety associated with oral health care: conceptual and clinical issues," in Behavioral Dentistry, D. Mostofsky and A. Fortune, Eds., pp. 165-192, John Wiley and Sons, Ames, Iowa, USA, 2nd edition, 2014.

[23] J. M. Armfield, G. D. Slade, and A. J. Spencer, "Dental fear and adult oral health in Australia," Community Dentistry and Oral Epidemiology, vol. 37, no. 3, pp. 220-230, 2009.

[24] D. W. McNeil and M. L. Berryman, "Components of dental fear in adults?" Behaviour Research and Therapy, vol. 27, no. 3, pp. 233-236, 1989.

[25] M. Mehrstedt, M. T. John, S. Tönnies, and W. Micheelis, "Oral health-related quality of life in patients with dental anxiety," Community Dentistry and Oral Epidemiology, vol. 35, no. 5, pp. 357-363, 2007.

[26] J. Vermaire, C. van Houtem, J. Ross, and A. Schuller, "The burden of disease of dental anxiety: generic and disease-specific quality of life in patients with and without extreme levels of dental anxiety," European Journal of Oral Sciences, vol. 124, no. 5, pp. 454-458, 2016.

[27] O. Schierz, M. T. John, D. R. Reißmann, M. Mehrstedt, and A. Szentpétery, "Comparison of perceived oral health in patients with temporomandibular disorders and dental anxiety using oral health-related quality of life profiles," Quality of Life Research, vol. 17, no. 6, pp. 857-866, 2008.

[28] S. K. S. Ng and W. K. Leung, "A community study on the relationship of dental anxiety with oral health status and oral health-related quality of life," Community Dentistry and Oral Epidemiology, vol. 36, no. 4, pp. 347-356, 2008.

[29] D. E. Polk, R. J. Weyant, R. J. Crout et al., "Study protocol of the center for oral health research in appalachia (COHRA) etiology study," BMC Oral Health, vol. 8, no. 1, article 18, 2008.

[30] R. A. Kleinknecht, R. K. Klepac, and L. D. Alexander, "Origins and characteristics of fear of dentistry," The Journal of the American Dental Association, vol. 86, no. 4, pp. 842-848, 1973.

[31] R. A. Kleinknecht, R. M. Thorndike, F. D. McGlynn, and J. Harkavy, "Factor analysis of the dental fear survey with crossvalidation," The Journal of the American Dental Association, vol. 108, no. 1, pp. 59-61, 1984.

[32] F. D. McGlynn, D. W. McNeil, S. L. Gallagher, and S. Vrana, "Factor structure, stability, and internal consistency of the dental fear survey," Behavioral Assessment, vol. 9, no. 1, pp. 5766, 1987.

[33] M. Hakeberg and U. Berggren, "Dimensions of the dental fear survey among patients with dental phobia," Acta Odontologica Scandinavica, vol. 55, no. 5, pp. 314-318, 1997.

[34] T. Smith and R. A. Moore, "Repression of dental anxiety," Journal of Dental Research, vol. 74, p. 144, 1995.

[35] J. F. Wilson and S. A. Sinisko, "Increased self-reported dental anxiety following completion of a dental history questionnaire," Psychological Reports, vol. 81, no. 1, pp. 59-62, 1997.

[36] J. Cesar, A. B. A. de Moraes, P. Milgrom, and R. A. Kleinknecht, "Cross validation of a Brazilian version of the Dental Fear Survey," Community Dentistry and Oral Epidemiology, vol. 21, no. 3, pp. 148-150, 1993.

[37] P. Milgrom, R. A. Kleinknecht, J. Elliott, L. H. Hsing, and T. Choo-Soo, "A cross-cultural cross validation of the dental fear survey in South East Asia," Behaviour Research and Therapy, vol. 28, no. 3, pp. 227-233, 1990.

[38] D. W. McNeil and A. J. Rainwater III, "Development of the fear of pain questionnaire-III," Journal of Behavioral Medicine, vol. 21, no. 4, pp. 389-410, 1998.

[39] G. D. Slade and A. J. Spencer, "Development and evaluation of the oral health impact profile," Community dental health, vol. 11, no. 1, pp. 3-11, 1994.

[40] B. H. De Oliveira and P. Nadanovsky, "Psychometric properties of the Brazilian version of the Oral Health Impact Profile-short form," Community Dentistry and Oral Epidemiology, vol. 33, no. 4, pp. 307-314, 2005.

[41] V. Papagiannopoulou, C. J. Oulis, W. Papaioannou, G. Antonogeorgos, and J. Yfantopoulos, "Validation of a Greek version of the oral health impact profile (OHIP-14) for use among adults," Health and Quality of Life Outcomes, vol. 10, article 7, 2012.

[42] K. Rener-Sitar, N. Petričević, A. Čelebić, and L. Marion, "Psychometric properties of Croatian and Slovenian short form of oral health impact profile questionnaires," Croatian Medical Journal, vol. 49, no. 4, pp. 536-544, 2008.

[43] G. D. Slade, "Derivation and validation of a short-form oral health impact profile," Community Dentistry and Oral Epidemiology, vol. 25, no. 4, pp. 284-290, 1997. 
[44] M. T. John, D. R. Reissmann, L. Feuerstahler et al., "Exploratory factor analysis of the oral health impact profile," Journal of Oral Rehabilitation, vol. 41, no. 9, pp. 635-643, 2014.

[45] M. T. John, L. Feuerstahler, N. Waller et al., "Confirmatory factor analysis of the oral health impact profile," Journal of Oral Rehabilitation, vol. 41, no. 9, pp. 644-652, 2014.

[46] M. T. John, D. R. Reissmann, A. Čelebić et al., "Integration of oral health-related quality of life instruments," Journal of Dentistry, vol. 53, pp. 38-43, 2016.

[47] C. M. dos Santos, B. H. de Oliveira, P. Nadanovsky, J. B. Hilgert, R. K. Celeste, and F. N. Hugo, "The Oral Health Impact Profile14: a unidimensional scale?” Cadernos de Saude Publica, vol. 29, no. 4, pp. 749-757, 2013.

[48] D. E. Polk, X. Wang, E. Feingold et al., "Effects of smoking and genotype on the PSR index of periodontal disease in adults aged 18-49," International Journal of Environmental Research and Public Health, vol. 9, no. 8, pp. 2839-2850, 2012.

[49] J. R. Shaffer, D. E. Polk, X. Wang et al., "Genome-wide association study of periodontal health measured by probing depth in adults ages 18-49 years," G3: Genes, Genomes, Genetics, vol. 4, no. 2, pp. 307-314, 2014.

[50] R. G. Landry and M. Jean, "Periodontal Screening and Recording (PSR) index: precursors, utility, and limitations in a clinical setting," International Dental Journal, vol. 52, no. 1, pp. 35-40, 2002.

[51] J. Wang and X. Wang, Structural Equation Modeling: Applications Using Mplus, Higher Education Press, West Sussex, UK, 2012.

[52] T. Z. Keith, Multiple Regression and Beyond: An Introduction to Multiple Regression and Structural Equation Modeling, Routledge, New York, NY, USA, 2nd edition, 2015.

[53] R. B. Kline, Principles and Practice of Structural Equation Modeling, Guilford Press, New York, NY, USA, 2015.

[54] R. J. Little and D. B. Rubin, Statistical Analysis with Missing Data, John Wiley \& Sons, Hoboken, NJ, USA, 2002.

[55] L. K. Muthén and B. O. Muthén, Mplus User's Guide, Muthén \& Muthén, Los Angeles, Calif, USA, 7th edition, 1998-2015.

[56] C. K. Enders, Applied Missing Data Analysis, Guilford Press, 2010.

[57] L.-T. Hu and P. M. Bentler, "Fit indices in covariance structure modeling: sensitivity to underparameterized model misspecification," Psychological Methods, vol. 3, no. 4, pp. 424-453, 1998.

[58] L.-T. Hu and P. M. Bentler, "Cutoff criteria for fit indexes in covariance structure analysis: conventional criteria versus new alternatives," Structural Equation Modeling, vol. 6, no. 1, pp. 1$55,1999$.

[59] B. N. Kyle, D. W. Mcneil, B. Weaver, and T. Wilson, "Recall of dental pain and anxiety in a cohort of oral surgery patients," Journal of Dental Research, vol. 95, no. 6, pp. 629-634, 2016.

[60] D. W. McNeil, A. J. Helfer, B. D. Weaver, R. W. Graves, B. N. Kyle, and A. M. Davis, "Memory of pain and anxiety associated with tooth extraction," Journal of Dental Research, vol. 90, no. 2, pp. 220-224, 2011.

[61] R. J. Crout, G. Koraido, and P. A. Moore, "A clinical trial of longacting local anesthetics for periodontal surgery," Anesthetic Progress, vol. 37, no. 4, pp. 194-198, 1990.

[62] R. C. Wiener, R. J. Crout, J. Sandell et al., "Local anesthetic syringe ergonomics and student preferences," Journal of Dental Education, vol. 73, no. 4, pp. 518-522, 2009.

[63] R. A. Boyce, T. Kirpalani, and N. Mohan, "Updates of topical and local anesthesia agents," Dental Clinics of North America, vol. 60, no. 2, pp. 445-471, 2016.
[64] M. Franz-Montan, L. N. Ribeiro, M. C. Volpato et al., "Recent advances and perspectives in topical oral anesthesia," Expert Opinion on Drug Delivery, 2016.

[65] E. V. Hersh, A. Pinto, M. Saraghi et al., "Double-masked, randomized, placebo-controlled study to evaluate the efficacy and tolerability of intranasal K305 (3\% tetracaine plus $0.05 \%$ oxymetazoline) in anesthetizing maxillary teeth," Journal of the American Dental Association, vol. 147, no. 4, pp. 278-287, 2016. 


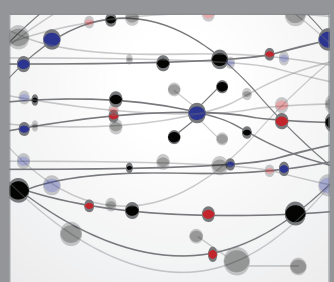

The Scientific World Journal
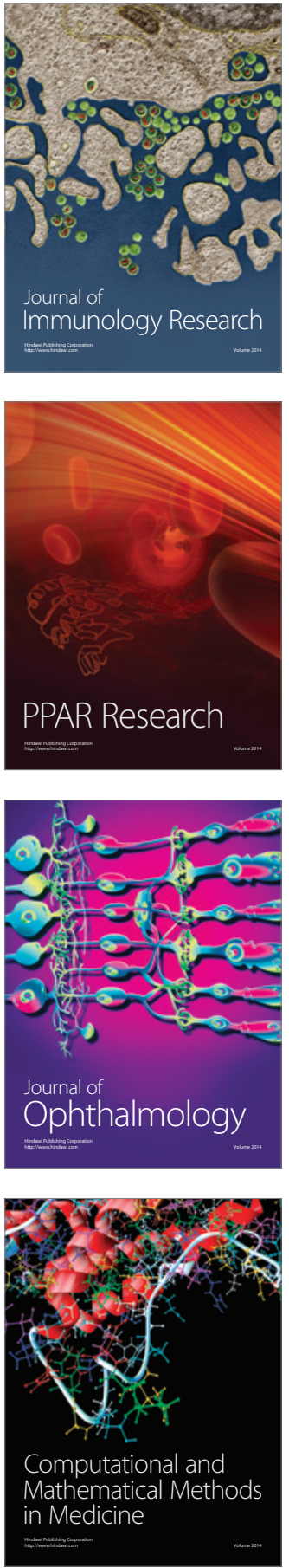

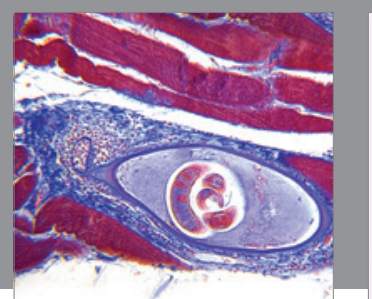

Gastroenterology Research and Practice
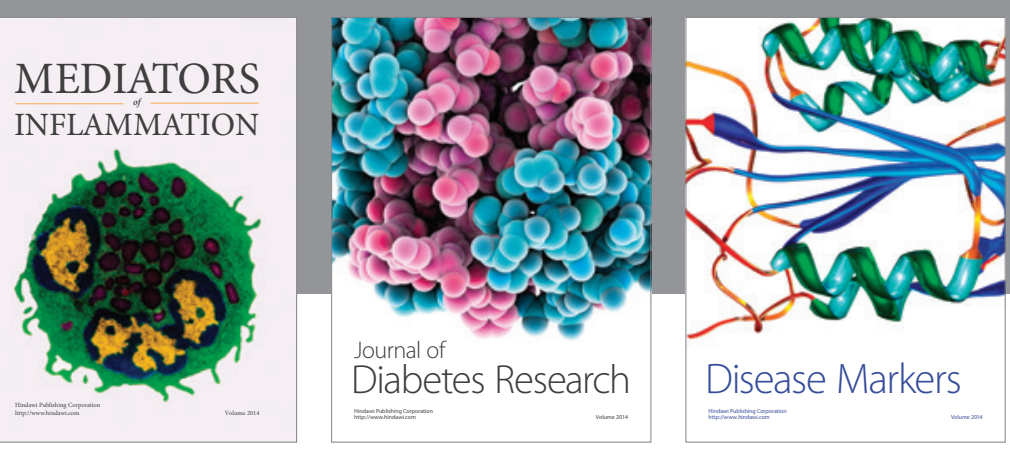

Disease Markers

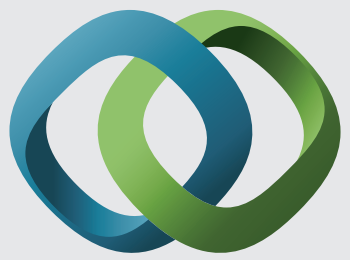

\section{Hindawi}

Submit your manuscripts at

https://www.hindawi.com
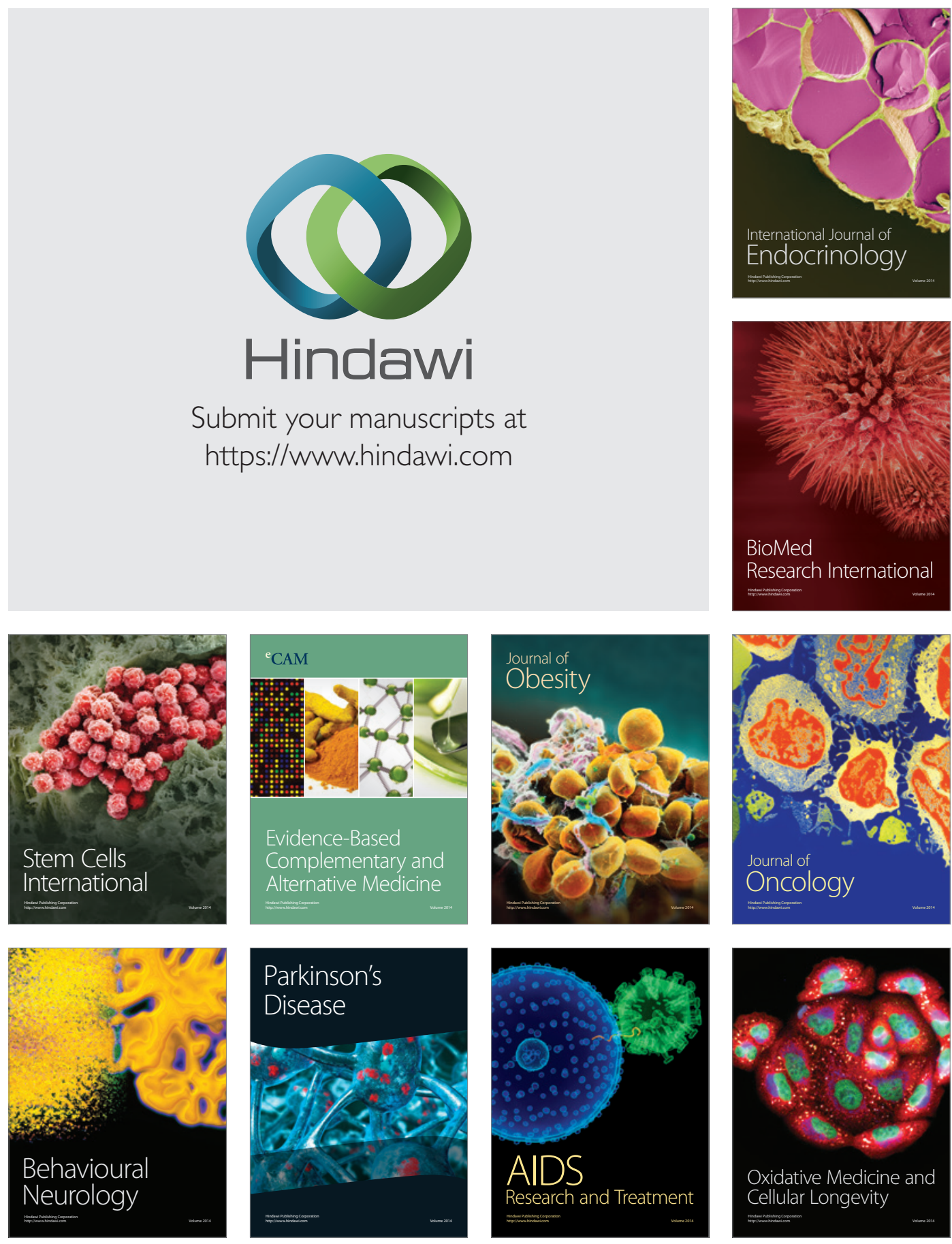